\title{
A Novel Dairy Fermented Frozen Dessert with Honey and Pomegranate Juice: Physicochemical, Rheological and Sensory Properties
}

\author{
Alexandros Petridis ${ }^{1}$, Dimitris Petridis ${ }^{1} \&$ Georgia Dimitreli $^{1}$ \\ ${ }^{1}$ Department of Food Science and Technology, International Hellenic University, Thessaloniki, Greece \\ Correspondence: Georgia Dimitreli, Department of Food Science and Technology, International Hellenic \\ University, P.O. Box 141, GR 57400, Thessaloniki, Greece. Tel: 30-231-001-3886. E-mail: dimitrel@ihu.gr
}

Received: September 14, 2020

Accepted: November 11, 2020

Online Published: November 18, 2020

doi:10.5539/jfr.v9n6p52

URL: https://doi.org/10.5539/jfr.v9n6p52

\begin{abstract}
The effect of fat content and added yoghurt, honey and pomegranate juice concentration on the overrun, and the physicochemical, rheological and sensory properties of frozen yoghurt samples was investigated, aiming in the production of a novel low-fat and functional dairy fermented frozen dessert. For this purpose, the methodology of mixture experiment was applied to twenty samples, while a control sample (without using honey and pomegranate juice) was also produced. According to the results, the increase in yoghurt concentration resulted in increasing $\mathrm{pH}$, overrun, brightness, elastic modulus $\left(\mathrm{G}^{\prime}\right)$ determined at $-2{ }^{\circ} \mathrm{C}$ and sensory hardness of the samples, while it reduced color parameters $\mathrm{a}^{*}$ and $\mathrm{b}^{*}$, creaminess, sweetness and fattiness. Increasing honey concentration reduced lactic acid concentration, $\mathrm{G}^{\prime}$ at $-2{ }^{\circ} \mathrm{C}$, hardness, sensory acidity, and to a lesser extent $\mathrm{pH}$, while increased color parameter $\mathrm{b}^{*}$, overrun, sensory color intensity, creaminess, sweetness, and fattiness of the samples. The increase in pomegranate juice concentration resulted in decreasing $\mathrm{pH}$, brightness and $\mathrm{b}^{*}$, as well as increasing $\mathrm{a}^{*}$, color intensity, creaminess and sensory acidity. Finally, fat, by interacting with one or two of the three constituents (yoghurt, honey and pomegranate juice), decreased $\mathrm{pH}$, creaminess and fattiness, while increased lactic acid concentration, $b^{*}$, color intensity and to a lesser degree the overrun level of the samples. Overall acceptability of the samples indicated that it is possible to use honey and pomegranate juice in the production of low-fat frozen yoghurt with favorable sensory properties.
\end{abstract}

Keywords: fat content, frozen yoghurt, honey, pomegranate juice, sensory properties

\section{Introduction}

Yoghurt, a fermented dairy product, is known for its health promoting properties and its high nutritional value. The increased value of yoghurt, when compared to milk, is due to the presence of beneficial bacteria and specific bioactive compounds. These ingredients, together with the nutritional profile of yoghurt, make it a particularly important dairy product, which is widely accepted worldwide and associated with a healthy diet (Tamime \& Robinson, 2007; Fernandez et al., 2017).

Ice cream is a dairy product that is consumed as an ice cream dessert and is prepared by freezing the ice cream mixture, with constant stirring (Deosarkar et al., 2016). It contains dairy and non-dairy ingredients (including sweetening agents) (Goff \& Hartel, 2013) and is proposed as an effective means of growth of probiotic organisms (Cruz et al., 2009). It is of great value, as it contains high quality protein and calcium, which is easily assimilated by the body. Today, ice creams of a wide variety of flavors are available (Deosarkar et al., 2016).

Frozen yoghurt is a complex dairy fermented frozen dessert. The increasing interest in frozen yoghurt is due to its desirable properties, as well as its nutritional value. It combines the cooling effect of ice cream with the sensory and nutritional properties of fermented milk products (Tamime \& Robinson, 2000; Pinto et al., 2012).

Consumers trends for a healthier diet has turned researchers interest in developing functional dairy desserts with low-fat content that are sugar-free and are further enriched with nutritional-functional additives.

Honey is a natural sweetener that can substitute sugar in many dairy products (Dimitreli et al., 2019; Sarkar \& Chandra, 2019), including frozen yoghurt, the use of which has not been reported so far. Honey has been used since ancient years due to its nutritional and therapeutic properties. Among other things, honey plays an 
important role as an antioxidant, anti-inflammatory and antibacterial agent (Meo et al., 2017).

Frozen yoghurt may contain numerous flavoring agents including fruit juices. Pomegranate is very popular, due to its biological effects, as it contains phenolic compounds, which account for strong antioxidant activity and specific physiological functions (antitumour, anti-inflammatory) (Gil et al., 2000; Karimi et al., 2017). Pomegranate juice have been used in many dairy and no-dairy beverages (Dimitreli et al., 2019), however, its use in frozen yoghurt has not been reported yet.

Therefore, the aim of the present work was to evaluate the effect of yoghurt concentration, honey and pomegranate juice addition, as well as fat content on the physicochemical, rheological and sensory properties of frozen yoghurt samples. The idea for this project came from the need to develop a functional low-fat, sugar-free, dairy dessert, which would combine the high nutritional value of yoghurt and the appealing characteristics of ice cream. For this reason, honey was used, instead of sugar, as a sweetening agent, while the nutritional value of the product was further enriched with the addition of pomegranate juice.

\section{Materials and Methods}

\subsection{Materials}

Semi-skimmed (1.5\% fat) pasteurized and homogenized bovine milk, milk cream, milk powder, pine honey, pomegranate juice and bottled water were purchased from the local market. For the preparation of pomegranate juice, the fruits are washed, drained, cut up and finally pressed. The extracted juice is filtered, pasteurized at $72{ }^{\circ} \mathrm{C}$ for $15 \mathrm{~s}$ and then packaged. Commercial Direct Vat Set type starter culture, consisting of Lactobacillus delbrueckii subsp. bulgaricus kal Streptococcus thermophilus (Jointex X3, Dosi 4; CSL Centro Spermentale, de Latte S.P.A, Zelo Buon Persico, Italy), and stabilizer (Cream Gold 50, Technoblend, Zona industrial JESCE sn, Matera, Italy) were also used for yoghurt and frozen yoghurt samples production, respectively.

\subsection{Preparation of Yoghurt}

The milk was heat treated at $95{ }^{\circ} \mathrm{C}$ for 5 min with constant stirring, cooled to $42{ }^{\circ} \mathrm{C}$, inoculated with the starter culture (according to the manufacturer's instructions) and incubated at $42^{\circ} \mathrm{C}$ for about $6 \mathrm{~h}$ until the pH reached 4.6. Following fermentation, the yoghurt was cooled to room temperature (approximately $20^{\circ} \mathrm{C}$ ), stirred and placed at $4{ }^{\circ} \mathrm{C}$ for $24 \mathrm{~h}$ before further using.

\subsection{Frozen Yoghurt Samples Production}

The chemical composition of the raw materials used for frozen yoghurt production is given in Table 1 . The preparation of the frozen yoghurt samples was based on the design of the mixture experiment, presented in Table 2. The amounts of the ingredients added (per $110 \mathrm{~g}$ of sample) ranged from 57 to $80 \mathrm{~g}$ for yoghurt, 6 to $18 \mathrm{~g}$ for honey and 0 to $15 \mathrm{~g}$ for pomegranate juice. Fat content was adjusted at two different percentages (levels) $1 \%$ and $3 \%$. The final proportion of the ingredients of the ice cream mixture (Table 3) was obtained by taking into account the chemical composition of the raw materials (Table 1) (yoghurt, milk cream, skimmed milk powder, honey) and the following equation that calculates the milk solids-not-fat content of each sample (honey concentration was expressed in dry basis):

$$
\text { Milk solids-not-fat }(\%)=[100-(\text { Fat } \%+\text { Honey } \%+\text { Stabilizer } \%)] / 7
$$

where Fat $\%$ is the final fat content of the samples, Honey $\%$ and Stabilizer $\%$ are the percentages of the ingredients added in the ice cream mixture. Equation 1 calculates the milk solids-not-fat that contribute to the freezing point depression, as a function of fat and non-dairy ingredients (sweetening agents, stabilizers) concentration, so as a balance of the ice cream mixture to be achieved.

For the needs of the experiment an additional sample (control) was prepared using sugar, as a sweetening agent, instead of honey (Table 3). Stabilizer was added at a percentage of $2.5 \%$ to all frozen yoghurt samples.

The ingredients of the ice cream mixture were mixed in the following order: water and milk cream were first mixed and heated at $50{ }^{\circ} \mathrm{C}$. The milk powder and the stabilizer were then added with simultaneous stirring until dissolve. The honey was incorporated into the mixture, which was then heat treated at $72{ }^{\circ} \mathrm{C}$ for $10 \mathrm{~min}$ and cooled to ambient temperature before yoghurt and pomegranate juice addition. The ice cream mixture was then placed at $4{ }^{\circ} \mathrm{C}$ for $24 \mathrm{~h}$. Following ripening, the mixture was frozen at $-6^{\circ} \mathrm{C}$ under continuous stirring, using a laboratory ice cream maker (Grand Gelato GIRMI). The frozen yoghurt samples were packaged into $200 \mathrm{~mL}$ plastic cups and stored at $-18{ }^{\circ} \mathrm{C}$ until further analysis. For oscillatory testing, the samples were placed into special made containers (see 2.6 subsection). Frozen yoghurt samples were produced in duplicate. 


\subsection{Physicochemical Analysis}

Physicochemical analysis of the frozen yoghurt samples involved $\mathrm{pH}$ (using a laboratory pH meter, GP353 ATC, EDT Instruments, Kent U.K.), acidity (expressed as lactic acid concentration \%, AOAC, 1998) and color determination using a tristimulus colorimeter (Micro Color LMC, Dr. Bruno Lange GmbH, Dusseldorf, Germany). The color components evaluated were $\mathrm{L}^{*}$ (brightness), $\mathrm{a}^{*}$ (+ red to - green component) and $\mathrm{b}^{*}$ (+ yellow to - blue component) of the CIE Lab scale (Hunter Lab format). Physicochemical measurements were conducted in triplicate.

Table 1. Chemical composition of the raw materials used for the production of frozen yoghurt

\begin{tabular}{lll}
\hline Raw materials & Dry matter (\%) & Fat (\%) \\
\hline Yoghurt & 10.10 & 1.4 \\
Milk cream & 40.50 & 35.0 \\
Skimmed milk powder & 82.10 & 0.8 \\
Honey & 82.74 & - \\
Pomegranate juice & 13.30 & - \\
\hline
\end{tabular}

Table 2. The mixture experiment design

\begin{tabular}{|c|c|c|c|c|}
\hline Sample & Yoghurt $(\mathrm{g})^{*}$ & Honey $(\mathrm{g})^{*}$ & Pomegranate juice $(\mathrm{g}) *$ & Fat $(\%)$ \\
\hline 1 & 80.0 & 6.0 & 4.0 & 1.0 \\
\hline 2 & 69.0 & 6.0 & 15.0 & 1.0 \\
\hline 3 & 57.0 & 18.0 & 15.0 & 1.0 \\
\hline 4 & 80.0 & 10.0 & 0.0 & 1.0 \\
\hline 5 & 72.0 & 18.0 & 0.0 & 1.0 \\
\hline 6 & 71.6 & 11.6 & 6.8 & 1.0 \\
\hline 7 & 75.8 & 8.8 & 5.4 & 1.0 \\
\hline 8 & 70.3 & 8.8 & 10.9 & 1.0 \\
\hline 9 & 64.3 & 14.8 & 10.9 & 1.0 \\
\hline 10 & 71.8 & 14.8 & 3.4 & 1.0 \\
\hline 11 & 80.0 & 6.0 & 4.0 & 3.0 \\
\hline 12 & 69.0 & 6.0 & 15.0 & 3.0 \\
\hline 13 & 57.0 & 18.0 & 15.0 & 3.0 \\
\hline 14 & 80.0 & 10.0 & 0.0 & 3.0 \\
\hline 15 & 72.0 & 18.0 & 0.0 & 3.0 \\
\hline 16 & 71.6 & 11.6 & 6.8 & 3.0 \\
\hline 17 & 75.8 & 8.8 & 5.4 & 3.0 \\
\hline 18 & 70.3 & 8.8 & 10.9 & 3.0 \\
\hline 19 & 64.3 & 14.8 & 10.9 & 3.0 \\
\hline 20 & 71.8 & 14.8 & 3.4 & 3.0 \\
\hline
\end{tabular}

* The amount of each component (except fat) is expressed as $\mathrm{g} / 110 \mathrm{~g}$ of sample

\subsection{Overrun Determination}

The overrun of the frozen yoghurt samples was calculated, as described in Goff and Hartel (2013), according to equation 2 .

$$
\text { Overrun } \%=\left[\left(\mathrm{W}_{1}-\mathrm{W}_{2}\right) / \mathrm{W}_{2}\right] \times 100
$$

where $\mathrm{W}_{1}$ is the weight of the ice cream mixture and $\mathrm{W}_{2}$ the weight of the same volume of ice cream.

\subsection{Rheological Measurements}

Rheological measurements of the frozen yoghurt samples were performed, using a DMA rheometer (Bohlin C-VOR 150, Malvern Instruments, Ltd, Worcestershire, UK), over a temperature range of $-2{ }^{\circ} \mathrm{C}$ to $30{ }^{\circ} \mathrm{C}$, stimulating the conditions that the sample melts into the mouth. A Peltier plate system $\left(-30\right.$ to $\left.+180{ }^{\circ} \mathrm{C}\right)$, adapted to the rheometer, was used for temperature control. Rheological measurements were conducted in triplicate.

For oscillatory testing a serrated plate and plate geometry was used in order to avoid slip effects. The upper plate that had a diameter of $40 \mathrm{~mm}$ was lowered toward the upper surface of the sample which was placed into 
specially made aluminium containers (10 $\mathrm{mm}$ height and $40 \mathrm{~mm}$ diameter). The height of the samples inside the containers was approximately $2000 \mu \mathrm{m}$. A strain deformation of $1.5 \times 10^{-5}$, which was within the linear viscoelastic region, at a frequency of $1 \mathrm{~Hz}$ was applied and the elastic $\left(\mathrm{G}^{\prime}\right)$ and viscous $\left(\mathrm{G}^{\prime \prime}\right)$ moduli of the samples over the set temperature range were recorded. From the derived mechanical spectra, the $\mathrm{G}^{\prime}$ and the loss tangent $(\tan \delta)$ at $-2{ }^{\circ} \mathrm{C}$ and $28^{\circ} \mathrm{C}$ were obtained.

The apparent viscosity of the samples was determined using a plate and cone geometry. Particularly, the instrument was equipped with a $4^{\circ}$ stainless steel cone that was lowered to the measuring position set at a 150 $\mu \mathrm{m}$ gap, after the sample was placed between the cone and the parallel plate-base of the rheometer. The applied strain was $40 \mathrm{~s}^{-1}$ (corresponding approximately to the strain applied to the sample during swallowing) (Omar et al., 1995). The apparent viscosity at $-2{ }^{\circ} \mathrm{C}$ and $28^{\circ} \mathrm{C}$ was obtained.

Table 3. The final ratio of the ingredients of the ice cream mixture (in g), corresponding to each sample (total mass: $100 \mathrm{~g}$ )

\begin{tabular}{llllllll}
\hline Sample & $\begin{array}{l}\text { Milk } \\
\text { cream }\end{array}$ & Yoghurt & Water & Honey & $\begin{array}{l}\text { Pomegranate } \\
\text { Juice }\end{array}$ & $\begin{array}{l}\text { Skimmed milk } \\
\text { powder }\end{array}$ & Stabilizer \\
\hline 1 & - & 72.8 & 8.6 & 6.6 & 3.6 & 5.9 & 2.5 \\
2 & 0.3 & 62.8 & 7.4 & 6.6 & 13.7 & 6.7 & 2.5 \\
3 & 0.9 & 51.9 & 5.3 & 19.7 & 13.7 & 6.0 & 2.5 \\
4 & - & 72.8 & 8.3 & 10.9 & - & 5.5 & 2.5 \\
5 & 0.3 & 65.5 & 7.0 & 19.7 & - & 5.0 & 2.5 \\
6 & 0.3 & 65.2 & 7.3 & 12.7 & 6.2 & 5.8 & 2.5 \\
7 & - & 69.0 & 8.1 & 9.6 & 4.9 & 5.9 & 2.5 \\
8 & 0.3 & 64.0 & 7.4 & 9.6 & 9.9 & 6.3 & 2.5 \\
9 & 0.6 & 58.5 & 6.4 & 16.2 & 9.9 & 5.9 & 2.5 \\
10 & 0.3 & 65.3 & 7.2 & 16.2 & 3.1 & 5.4 & 2.5 \\
11 & 5.7 & 72.8 & 3.4 & 6.6 & 3.6 & 5.4 & 2.5 \\
12 & 6.0 & 62.8 & 2.4 & 6.6 & 13.7 & 6.0 & 2.5 \\
13 & 6.6 & 51.9 & 0.3 & 19.7 & 13.7 & 5.3 & 2.5 \\
14 & 5.7 & 72.8 & 3.3 & 10.9 & - & 4.8 & 2.5 \\
15 & 6.0 & 65.5 & 1.9 & 19.7 & - & 4.4 & 2.5 \\
16 & 6.0 & 65.5 & 2.2 & 12.7 & 6.2 & 5.2 & 2.5 \\
17 & 5.7 & 69.0 & 3.0 & 9.6 & 4.9 & 5.3 & 2.5 \\
18 & 6.0 & 64.0 & 2.4 & 9.6 & 9.9 & 5.6 & 2.5 \\
19 & 6.3 & 58.5 & 1.3 & 16.2 & 9.9 & 5.3 & 2.5 \\
20 & 6.0 & 65.3 & 2.2 & 16.2 & 3.1 & 4.7 & 2.5 \\
\hline
\end{tabular}

Sample 21/ Control sample: Milk cream: 0.3 g; Yoghurt: 65.5 g; Water: 10.3 g; Sugar: 16.4 g; Pomegranate juice: $0.0 \mathrm{~g}$; Skimmed milk powder: $5.0 \mathrm{~g}$; Stabilizer: $2.5 \mathrm{~g}$.

\subsection{Sensory Analysis}

The sensory analysis design was a randomized balanced incomplete block design (BIB), which is characterized by the following parameters: $\mathrm{t}=21$ treatments (samples), $\mathrm{k}=5$ treatments assessed by each panelist, $\mathrm{b}=21$ panelists, $\mathrm{n}=5$ replicates of each treatment in the design and $\lambda=1$ pair of similar treatments. The design in question was carried out twice, so that totally 42 samples (including the control sample) were assessed by the panelists.

The sensory profile of the samples was evaluated by determining seven objective sensory variables (intensity of color, hardness, creaminess, intensity of typical yoghurt taste, sweetness, acidity and fattiness) and one subjective / "hedonic" variable (overall acceptability of the product). Trained panelists were asked to express their opinion for each sample and variable by ticking on an unstructured linear scale, whose length was $15 \mathrm{~cm}$ and whose left end $(0 \mathrm{~cm})$ was assigned as "not at all intensive" and the right end $(15 \mathrm{~cm})$ was assigned as "very intensive", except for the intensity of color (whose left end was assigned "very pink", its center was assigned "no color-white" and its right end was assigned as "very yellow-brown"). Both the order of the panelists and the sequence of the samples on each plate were previously randomized to avoid statistical bias.

Prior to the analysis, the samples were placed into cups made of Styrofoam, at a temperature range between -10 ${ }^{\circ} \mathrm{C}$ and $-6{ }^{\circ} \mathrm{C}$. Additionally, bottled water in a plastic glass was provided to each panelist in order to clean his 
palate during the time period between the samples.

\subsection{Statistical Analysis}

In the context of the statistical analysis, a mixture experiment design was utilized. Thirteen statistically significant response variables were analyzed and additionally three design variables / factors (yoghurt, honey and pomegranate juice) and one process variable (fat) were included in the design. Each response variable was regressed against the design variables and the process variable by applying the special cubic polynomial model, which is the most suitable model regarding the mixture experiment designs. All the terms were subjected to the forward selection model and only the statistically significant terms (including the factors which are always used) were included in the final equations. Reliability and validity of the regression equations were evaluated by observing the determined $\left(R^{2}\right)$, the adjusted $\left(R_{\text {adj }}^{2}\right)$ and the predicted regression coefficients $\left(R_{\text {pred }}^{2}\right)$ and the lack of fit test value $(P>0.05)$, respectively. It should be noted that the coefficients $R^{2}$ and $R^{2}$ pred should differ by a percentage lower than $20 \%$ in order to ensure an adequate reliability of the model.

In addition, main effect plots (corresponding to the process variable), contour plots and Cox response trace plots corresponding to the response variables were utilized to examine the particular trends that are developed between the response variables and the factors.

Finally, the method of MaxDiff was used, so as to find the most acceptable samples according to panelists' preference, and a proportion preference (Best-Worst scaling) for all treatments was derived.

\section{Results and Discussion}

The mean values of the physicochemical characteristics and overrun are shown in Table 4, while the mean values of the rheological and sensory properties are presented in Tables 5 and 6, respectively. Based on the results of the forward selection, reducing models in the form of polynomial equations were formed (Table 7).

Table 4. Mean values of the physicochemical properties and overrun of the frozen yoghurt samples

\begin{tabular}{lllllll}
\hline Sample & pH & Acidity (\% lactic acid) & $\mathbf{L}^{*}$ & $\mathbf{a}^{*}$ & $\mathbf{b}^{*}$ & Overrun (\%) \\
\hline 1 & 4.96 & 1.075 & 78.745 & 0.270 & 8.920 & 33.75 \\
2 & 4.68 & 1.180 & 73.115 & 3.145 & 7.370 & 35.75 \\
3 & 4.76 & 1.000 & 67.100 & 3.120 & 10.100 & 40.60 \\
4 & 4.99 & 0.850 & 88.355 & -2.490 & 13.045 & 37.70 \\
5 & 5.11 & 0.495 & 84.070 & -1.940 & 15.210 & 39.95 \\
6 & 4.86 & 0.920 & 74.280 & 1.220 & 9.230 & 36.55 \\
7 & 4.97 & 0.720 & 77.295 & 0.810 & 9.080 & 35.35 \\
8 & 4.57 & 1.005 & 74.645 & 1.850 & 8.210 & 36.40 \\
9 & 4.75 & 1.045 & 72.820 & 1.900 & 9.625 & 38.00 \\
10 & 4.94 & 0.920 & 75.185 & 0.260 & 10.850 & 37.15 \\
11 & 5.01 & 0.925 & 79.975 & 0.110 & 9.560 & 37.10 \\
12 & 4.67 & 1.125 & 72.025 & 2.740 & 8.190 & 41.65 \\
13 & 4.52 & 1.115 & 64.675 & 3.560 & 10.830 & 44.40 \\
14 & 4.92 & 0.890 & 86.515 & -2.020 & 14.500 & 40.75 \\
15 & 4.85 & 0.875 & 82.205 & -1.700 & 16.955 & 42.45 \\
16 & 4.78 & 1.015 & 74.630 & 0.880 & 10.905 & 40.90 \\
17 & 4.83 & 0.985 & 77.110 & 0.405 & 10.280 & 35.35 \\
18 & 4.81 & 1.080 & 73.320 & 1.570 & 9.595 & 37.90 \\
19 & 4.65 & 1.015 & 69.875 & 2.125 & 10.980 & 41.70 \\
20 & 4.82 & 1.050 & 75.650 & 0.480 & 12.005 & 36.80 \\
$21 *$ & 5.12 & 0.700 & 89.240 & -4.420 & 13.665 & 54.20 \\
\hline
\end{tabular}

*Sample 21 is the control frozen yoghurt sample

\subsection{Physicochemical Properties}

The $\mathrm{pH}$ values of the samples ranged from 4.52 to 5.12, while their acidity expressed as lactic acid concentration \%, ranged from $0.495 \%$ to $1.180 \%$ (Table 4). In general, samples with increased percentage of added yoghurt or/and increased pomegranate juice concentration exhibited lower $\mathrm{pH}$ values and increased lactic acid concentration, due to the low $\mathrm{pH}$ values of yoghurt and pomegranate juice (the $\mathrm{pH}$ values for yoghurt and pomegranate juice were 4.6 and 3.1 , respectively). 
Table 5. Mean values of the elastic modulus $\left(\mathrm{G}^{\prime}\right)$, $\tan \delta$ and apparent viscosity of the frozen yoghurt samples at two different temperatures $\left(-2{ }^{\circ} \mathrm{C}\right.$ and $\left.28^{\circ} \mathrm{C}\right)$.

\begin{tabular}{|c|c|c|c|c|c|c|}
\hline Sample & $\begin{array}{l}\mathrm{G}^{\prime} \\
\left(-2^{\circ} \mathrm{C}\right)(\mathrm{Pa})\end{array}$ & $\begin{array}{l}\mathbf{G}^{\prime} \\
\left(28^{\circ} \mathrm{C}\right)(\mathrm{Pa})\end{array}$ & $\begin{array}{l}\tan \delta \\
\left(-2{ }^{\circ} \mathrm{C}\right)\end{array}$ & $\begin{array}{l}\tan \delta \\
\left(28^{\circ} \mathrm{C}\right)\end{array}$ & $\begin{array}{l}\text { Viscosity } \\
\left(-2^{\circ} \mathrm{C}\right)(\mathrm{Pa} \cdot \mathrm{s})\end{array}$ & $\begin{array}{l}\text { Viscosity } \\
\left(28^{\circ} \mathrm{C}\right)(\mathrm{Pa} \cdot \mathrm{s})\end{array}$ \\
\hline 1 & 81.7 & 8.0 & 0.593 & 0.599 & 0.354 & 0.100 \\
\hline 2 & 73.7 & 7.4 & 0.683 & 0.700 & 0.145 & 0.081 \\
\hline 3 & 36.3 & 5.7 & 0.619 & 0.663 & 0.109 & 0.059 \\
\hline 4 & 66.5 & 10.6 & 0.721 & 0.728 & 0.122 & 0.075 \\
\hline 5 & 42.8 & 5.0 & 0.651 & 0.685 & 0.118 & 0.062 \\
\hline 6 & 63.0 & 10.4 & 0.691 & 0.700 & 0.217 & 0.076 \\
\hline 7 & 67.5 & 6.7 & 0.692 & 0.699 & 0.124 & 0.068 \\
\hline 8 & 68.4 & 6.9 & 0.706 & 0.717 & 0.121 & 0.062 \\
\hline 9 & 49.3 & 8.6 & 0.705 & 0.713 & 0.164 & 0.093 \\
\hline 10 & 50.3 & 8.9 & 0.678 & 0.684 & 0.169 & 0.081 \\
\hline 11 & 70.6 & 7.6 & 0.779 & 0.790 & 0.266 & 0.084 \\
\hline 12 & 68.9 & 8.2 & 0.703 & 0.720 & 0.238 & 0.103 \\
\hline 13 & 36.4 & 5.3 & 0.677 & 0.694 & 0.129 & 0.067 \\
\hline 14 & 63.0 & 9.5 & 0.708 & 0.723 & 0.123 & 0.066 \\
\hline 15 & 35.4 & 6.0 & 0.620 & 0.660 & 0.120 & 0.063 \\
\hline 16 & 64.6 & 9.8 & 0.700 & 0.714 & 0.129 & 0.068 \\
\hline 17 & 70.1 & 8.2 & 0.663 & 0.673 & 0.128 & 0.066 \\
\hline 18 & 67.4 & 9.1 & 0.686 & 0.845 & 0.125 & 0.078 \\
\hline 19 & 49.7 & 7.7 & 0.574 & 0.600 & 0.158 & 0.082 \\
\hline 20 & 53.2 & 9.2 & 0.616 & 0.626 & 0.132 & 0.080 \\
\hline 21 & 69.6 & 13.3 & 0.880 & 0.901 & 0.229 & 0.093 \\
\hline
\end{tabular}

*Sample 21 is the control frozen yoghurt sample

Table 6. Mean values of the sensory (objective) variables of the frozen yoghurt samples

\begin{tabular}{llllllll}
\hline Sample & Color & Hardness & Creaminess & Yoghurt taste & Sweetness & Acidity & Fattiness \\
\hline 1 & 6.7 & 9.6 & 3.0 & 4.6 & 3.8 & 6.7 & 3.1 \\
2 & 2.5 & 10.8 & 3.8 & 7.5 & 3.8 & 8.4 & 5.0 \\
3 & 5.9 & 1.6 & 10.8 & 5.8 & 10.2 & 6.7 & 7.6 \\
4 & 8.0 & 7.8 & 7.0 & 5.5 & 4.7 & 3.9 & 4.8 \\
5 & 8.2 & 4.2 & 11.5 & 4.9 & 10.9 & 4.2 & 11.7 \\
6 & 5.5 & 9.8 & 8.2 & 10.6 & 7.0 & 8.7 & 9.4 \\
7 & 8.4 & 11.0 & 5.2 & 6.9 & 5.2 & 7.7 & 5.4 \\
8 & 6.7 & 8.3 & 6.9 & 4.8 & 5.0 & 7.1 & 4.9 \\
9 & 4.9 & 4.7 & 11.5 & 5.4 & 8.5 & 9.5 & 6.1 \\
10 & 7.4 & 5.0 & 11.6 & 6.1 & 7.8 & 4.5 & 9.6 \\
11 & 7.4 & 11.9 & 5.5 & 6.3 & 1.8 & 6.8 & 1.5 \\
12 & 5.6 & 10.8 & 3.8 & 7.5 & 2.9 & 9.1 & 2.4 \\
13 & 12.5 & 2.4 & 6.4 & 4.3 & 10.6 & 6.1 & 7.0 \\
14 & 8.1 & 13.1 & 5.3 & 7.0 & 2.8 & 4.7 & 3.0 \\
15 & 8.6 & 3.3 & 8.4 & 6.8 & 11.1 & 4.2 & 7.7 \\
16 & 8.4 & 9.0 & 4.7 & 7.2 & 6.0 & 7.3 & 5.9 \\
17 & 7.1 & 11.0 & 4.1 & 7.6 & 4.7 & 8.1 & 5.0 \\
18 & 5.5 & 12.3 & 4.2 & 6.5 & 2.3 & 7.4 & 3.4 \\
19 & 8.7 & 5.7 & 8.3 & 6.9 & 8.1 & 7.3 & 5.8 \\
20 & 8.2 & 7.2 & 9.1 & 6.9 & 10.2 & 4.7 & 6.5 \\
21 & 7.7 & 6.7 & 10.7 & 7.0 & 11.0 & 3.6 & 8.9 \\
\hline
\end{tabular}

*Sample 21 is the control frozen yoghurt sample

As it can be seen in Cox response trace plots for $\mathrm{pH}$ shown in Figure 1 (A and B), fat significantly affected the change in $\mathrm{pH}$, regulating the action of yoghurt and honey. Particularly, the increase in fat content from $1 \%$ to $3 \%$ 
followed by the simultaneously increase in the concentration of added yoghurt resulted in increasing the $\mathrm{pH}$ of the samples. Furthermore, increasing fat and honey concentration resulted in reducing samples $\mathrm{pH}$, however this change was weaker than the change caused by the yoghurt-fat interaction (Table 7). At an individual level, yoghurt increased samples $\mathrm{pH}$ regardless fat content, but this happened more strongly at $3 \%$ fat concentration. Pomegranate juice had a permanent negative effect, which was strong in both $1 \%$ and $3 \%$ fat content. Finally, honey raised the $\mathrm{pH}$ at $1 \%$ fat content but when the amount of the latter was increased the change was reversed, resulting in a $\mathrm{pH}$ decrease. The effect of honey, yoghurt, pomegranate juice and fat on the $\mathrm{pH}$ of the samples depends on the $\mathrm{pH}$ value of these ingredients, their concentration in the ice cream mixture, as well as the concentration of the other ingredients that also affect $\mathrm{pH}$. The $\mathrm{pH}$ values of all ice cream mixture components were: yoghurt 4.6, honey 5.0, pomegranate juice 3.1, cream 6.7 and water 7.8. Regarding the effect of fat, it is worth noting that the increase in its concentration, which was achieved by the addition of milk cream, reduced the amount of water required. As water has a fairly high $\mathrm{pH}$ value (the largest of all the ingredients) reducing its percentage in the ice cream mixture resulted in reducing the $\mathrm{pH}$ value of the samples.

Figure 1 ( $\mathrm{C}$ and $\mathrm{D})$ shows a clear increase in acidity when the amount of pomegranate juice increases and the concentration of yoghurt and honey decreases. Pomegranate juice affected samples acidity the most (Table 7), while the change caused by it was of the same intensity in both $1 \%$ and $3 \%$ fat content. In addition, increasing the percentage of fat and reducing the percentage of yoghurt and honey caused an increase in acidity and, if they were accompanied by an increase in the pomegranate juice concentration, led to quite high levels of lactic acid concentration. Yoghurt slightly reduced acidity at $3 \%$ fat content, but practically did not change it at all when the fat content was reduced (1\%). Finally, increasing honey concentration reduced samples acidity regardless of the fat content, however, the change was relatively stronger at $1 \%$ fat content. The acidity of the samples was affected by their $\mathrm{pH}$ value. Therefore, reduced $\mathrm{pH}$ values led to an increase in samples acidity. However, the action of the various components on the acidity of the samples did not correspond exactly to the action on their $\mathrm{pH}$, due to the presence of milk proteins into the ice cream system that possess strong buffering capacity (Salaïn et a., 2005).

Table 7. The polynomial equations and the $\mathrm{R}^{2}$ and $\mathrm{R}_{\mathrm{p}}^{2}$ coefficients that correspond to the statistically significant response variables

\begin{tabular}{llll}
\hline Response variable & Polynomial equation & $\mathbf{R}^{2}(\%)$ & $\mathbf{R}_{\mathbf{p}}^{2}(\boldsymbol{\%})$ \\
\hline $\mathrm{pH}$ & $5.06 \mathrm{x}_{1}+4.48 \mathrm{x}_{2}+3.09 \mathrm{x}_{3}+0.07 \mathrm{x}_{1} \mathrm{~V}-0.80 \mathrm{x}_{2} \mathrm{~V}$ & 91.83 & 89.34 \\
Acidity (\% lactic acid) & $0.93 \mathrm{x}_{1}+0.14 \mathrm{x}_{2}+2.63 \mathrm{x}_{3}+0.53 \mathrm{x}_{1} \mathrm{x}_{2} \mathrm{~V}$ & 65.52 & 56.82 \\
$\mathrm{~L}^{*}$ & $87.49 \mathrm{x}_{1}+54.39 \mathrm{x}_{2}-2.24 \mathrm{x}_{3}$ & 85.07 & 82.51 \\
$\mathrm{a}^{*}$ & $-1.54 \mathrm{x}_{1}-0.87 \mathrm{x}_{2}+27.05 \mathrm{x}_{3}$ & 92.77 & 91.61 \\
$\mathrm{~b}^{*}$ & $9.32 \mathrm{x}_{1}+37.12 \mathrm{x}_{2}-17.81 \mathrm{x}_{3}+0.77 \mathrm{x}_{1} \mathrm{~V}$ & 84.97 & 81.20 \\
Overrun (\%) & $33.02 \mathrm{x}_{1}+68.32 \mathrm{x}_{2}+44.43 \mathrm{x}_{3}$ & 63.29 & 55.80 \\
$\mathrm{G}^{\prime}\left(-2^{\circ} \mathrm{C}\right)$ & $96.30 \mathrm{x}_{1}-177.10 \mathrm{x}_{2}+71.90 \mathrm{x}_{3}$ & 93.11 & 91.85 \\
Hardness & $18.14 \mathrm{x}_{1}-55.08 \mathrm{x}_{2}+8.50 \mathrm{x}_{3}$ & 85.10 & 82.86 \\
Creaminess & $1.85 \mathrm{x}_{1}+44.58 \mathrm{x}_{2}+0.46 \mathrm{x}_{3}-9.98 \mathrm{x}_{2} \mathrm{~V}$ & 73.03 & 65.72 \\
Color & $7.30 \mathrm{x}_{1}+16.65 \mathrm{x}_{2}-5.02 \mathrm{x}_{3}+36.05 \mathrm{x}_{2} \mathrm{x}_{3} \mathrm{~V}$ & 41.51 & 23.19 \\
Sweetness & $-1.90 \mathrm{x}_{1}+59.97 \mathrm{x}_{2}+1.21 \mathrm{x}_{3}$ & 86.90 & 84.78 \\
Sensory Acidity & $7.32 \mathrm{x}_{1}-12.92 \mathrm{x}_{2}+28.99 \mathrm{x}_{3}$ & 61.52 & 54.58 \\
Fattiness & $0.59 \mathrm{x}_{1}+39.20 \mathrm{x}_{2}+1.82 \mathrm{x}_{3}-9.73 \mathrm{x}_{1} \mathrm{x}_{2} \mathrm{~V}$ & 80.26 & 71.73 \\
\hline
\end{tabular}

$\mathrm{G}^{\prime}\left(-2{ }^{\circ} \mathrm{C}\right)$ is the elastic modulus measured at $-2{ }^{\circ} \mathrm{C} ; \mathrm{R}^{2}$ is the predicted $\mathrm{R}^{2}$

According to the results shown in Table 4, the brightness of the samples ranged from 64 to 89 . In general the samples could be characterized from moderate to quite white. As it concerns the color parameter $\mathrm{a}^{*}$, its values ranged from negative ( -4.42$)$ (increased green color intensity) to positive (3.56) (increased red color intensity) values. Finally, all samples showed positive values of the parameter $b^{*}$, which ranged from 7.3 to 16.9. This implies that all samples exhibited yellow color.

As shown in Figure 2A, the increase in the amount of added yoghurt significantly increased samples brightness, while a reverse change of slightly greater intensity was observed with increasing pomegranate juice concentration and reducing yoghurt and honey concentration (Table 7). In addition, by consulting the Cox response trace plot of Figure 2A and the regression coefficients of Table 7 for $\mathrm{L}^{*}$, honey and fat had no effect on samples brightness. The increase in white color intensity with increasing yoghurt concentration is due to the presence of caseins, which are present in the frozen yoghurt system in the form of casein micelles. Increasing the 
concentration of casein micelles increases the reflection of light (Walstra et al., 2006) resulting in increased samples brightness. The red color of the pomegranate juice was responsible for reducing samples brightness. Reduced values of brightness in kefir-type products with increasing pomegranate concentration were also reported by Dimitreli et al. (2019).

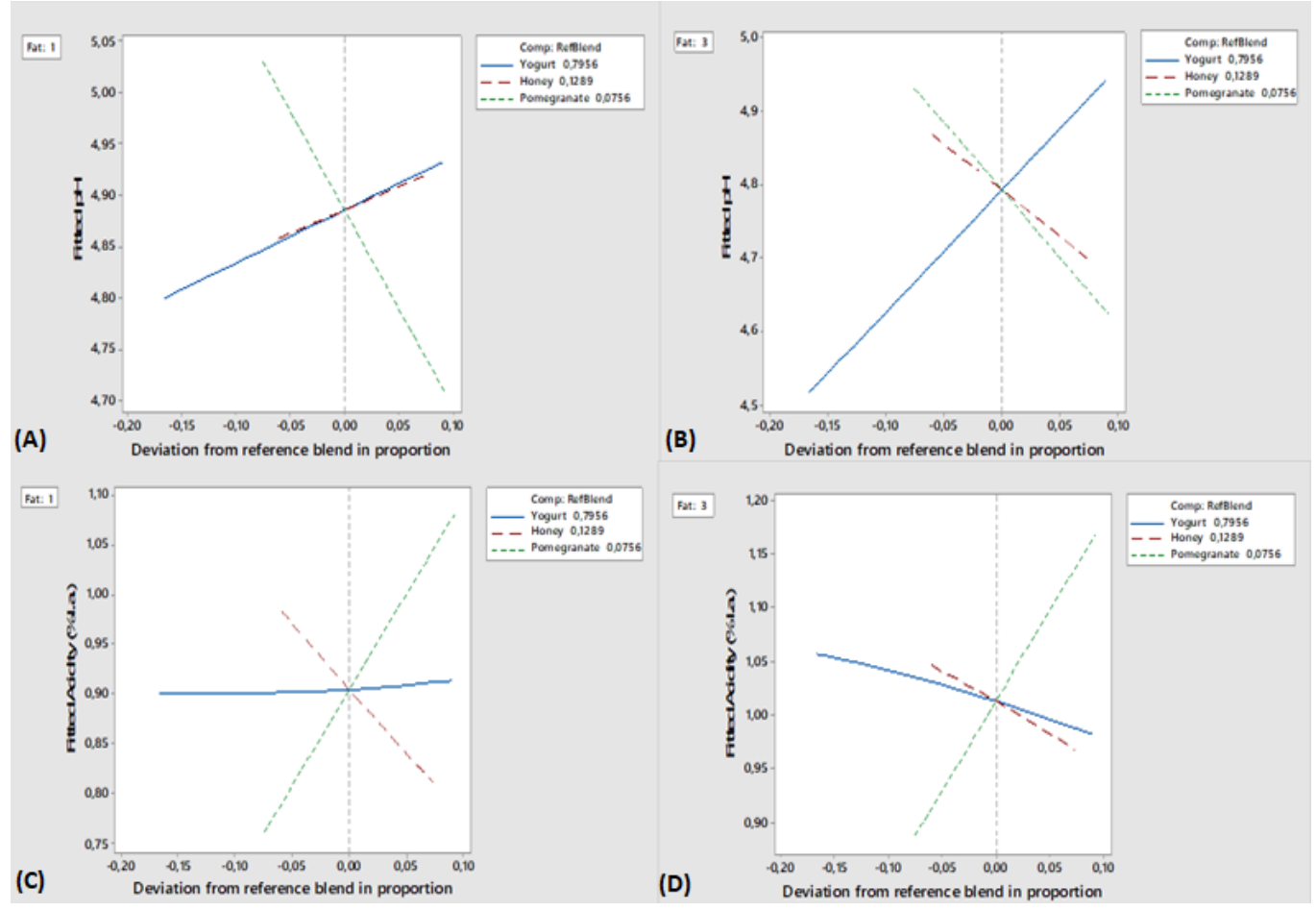

Figure 1. The Cox response trace plots at $1 \%$ and $3 \%$ fat content levels corresponding to $\mathrm{pH}$ ( $\mathrm{A}$ and $\mathrm{B}$, respectively) and acidity (\% lactic acid) ( $\mathrm{C}$ and $\mathrm{D}$, respectively). The effect of yoghurt is marked in blue, the effect of honey is marked in red and the effect of the pomegranate juice is marked in green

Pomegranate juice was almost entirely responsible for the change of $\mathrm{a}^{*}$ (Figure 2B, Table 7), the increase of which significantly increased the variable, enhancing the presence of red color in the samples. On the other hand, honey practically did not affect the response variable at all, while the increase in yoghurt concentration and the corresponding reduction of pomegranate and honey slightly reduced the value of $\mathrm{a}^{*}$. This resulted in reducing red color intensity of the samples and enhancing green color intensity (leading the variable in negative values). The red color of pomegranate juice is responsible for increasing the intensity of the red color of frozen yoghurt samples. Similar results concerning pomegranate juice were reported by Dimitreli et al. (2019) for kefir-type products. The decrease in the values of $\mathrm{a}^{*}$ to negative values with the increase in yoghurt concentration, is due to the presence of riboflavin in milk. Riboflavin is a pigment, which has a yellow-green color (Walstra et al., 2006).

As shown in Figure $2(\mathrm{C}$ and $\mathrm{D}$ ) and Table 7, the interaction of yoghurt with fat (the increase in fat content from $1 \%$ to $3 \%$ in combination with yoghurt increase) had a positive effect on $\mathrm{b}^{*}$. The yellow color intensity was also enhanced by the increase in honey concentration and the parallel decrease in the percentages of the other ingredients. On the contrary, the increase in pomegranate juice concentration resulted in reduced values of $b^{*}$, and the same change but of lesser intensity, was observed when the concentration of yoghurt increased. The increase in yellow color intensity with the interaction of fat and yoghurt can be attributed to the presence of carotenes into the milk, which are yellow in color and are found in fat globules (Walstra et al., 2006). The milk cream, which increases the fat content of the samples, contains higher concentration of carotenes than milk and therefore has a more significant effect on the yellow color intensity of the samples when compared to yoghurt. This means that the decrease in yoghurt concentration in combination with the decrease in the percentage of pomegranate juice (which also affects negatively the intensity of yellow color) and the simultaneous increase in the percentage of honey increase the intensity of the yellow color of yoghurt samples. Honey increases yellow color intensity due to the increased values of $b^{*}$ that exhibits (Karabagias et al., 2014). 


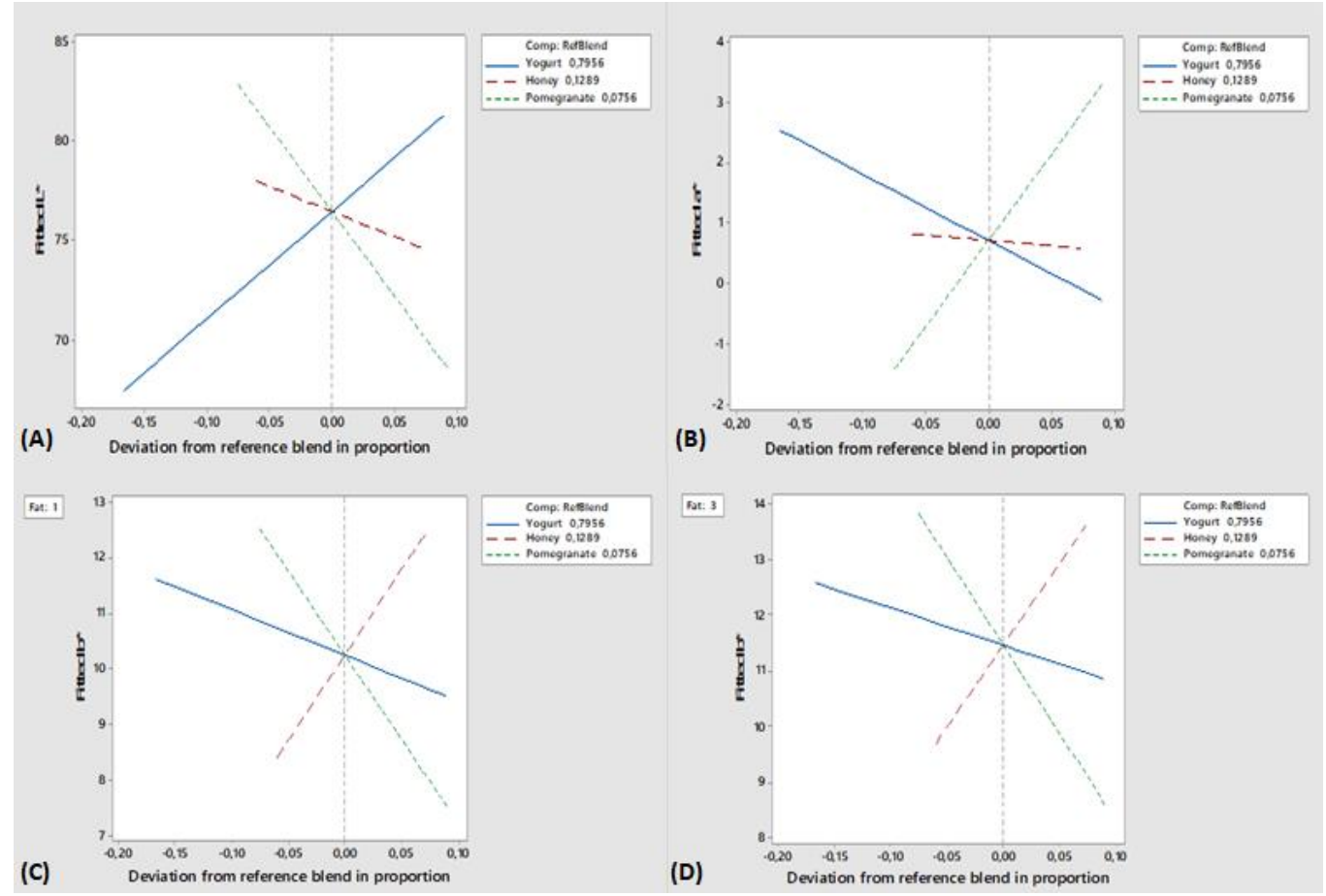

Figure 2. The Cox response trace plot corresponding to $\mathrm{L}^{*}(\mathrm{~A})$ and $\mathrm{a}^{*}(\mathrm{~B})$, as well as the Cox response trace plots at $1 \%$ and $3 \%$ fat content levels corresponding to $b^{*}$ (C and D, respectively). Graphs A and B present the same effect of the factors on each response variable at both the fat levels (1\% and 3\%). The effect of yoghurt is marked in blue, the effect of honey is marked in red and the effect of the pomegranate juice is marked in green

\subsection{Overrun}

As it can be seen in Table 4, the control sample showed the highest value of overrun (54.20\%). In general, the overrun level of frozen yoghurt samples ranged from $33.75 \%$ to $44.40 \%$. Similar overrun levels $(49.5 \pm 1.5 \%)$ are reported in the literature for frozen yoghurt samples made with caprine milk (Martinou-Voulasiki \& Zerfiridis, 1990).

The interaction of yoghurt with pomegranate and fat benefited the slightly increase of the overrun levels, especially when the fat content increased from $1 \%$ to $3 \%$ and the concentration of pomegranate juice was also increased (Figure 3A and B). Increasing the amount of honey led to a definite increase in overrun, especially at $1 \%$ fat concentration. Yoghurt sharply reduced overrun when the percentage of fat increased to 3\%, while its effect was less at $1 \%$ fat content. Finally, pomegranate juice reduced the overrun at $1 \%$ fat concentration and increased it at 3\%. The increase was aided by the interaction with fat, which exerts a positive effect on the response variable. The positive effect of fat on the overrun levels of the samples may be due to the presence of proteins into the membrane of fat globules, which have the ability to incorporate air bubbles into the mixture (Walstra et al., 2006). The increase in overrun values with increasing honey concentration might be probably also attributed to the presence of proteins into the honey. As it concerns the effect of yoghurt, by reducing its percentage into the ice cream mixture, an additional amount of skimmed milk powder is required to be used, which in turn increases the percentage of proteins into the ice cream system, thus resulting in increased air bubbles incorporation. Pomegranate juice affects the overrun in different ways depending on the fat content of the samples. This is probably due to the variation in the concentration of the other ingredients that affects overrun levels, due to the addition of juice.

\subsection{Rheological Properties}

As it can be seen in Table $5, \mathrm{G}^{\prime}$ at $-2{ }^{\circ} \mathrm{C}$ ranged from $81.7 \mathrm{~Pa}$ to $35.4 \mathrm{~Pa}$, while temperature increase $\left(28{ }^{\circ} \mathrm{C}\right)$ resulted in decreasing values of elasticity for all frozen yoghurt samples. This is due to the melting of the samples resulting in increasing their viscous behavior. As for tan $\delta$, its values at $-2{ }^{\circ} \mathrm{C}$, ranged from 0.570 to 0.880 , indicating that frozen yoghurt samples can be described as elastic, since they exhibited $\tan \delta$ values lower than one. However, with temperature increase, the values of $\tan \delta$ did not show a significant increase, as would be expected. This can be probably attributed to the presence of proteins and stabilizers into the ice cream system 
that form strong intermolecular interactions and help maintain the elasticity of the samples regardless temperature increase.
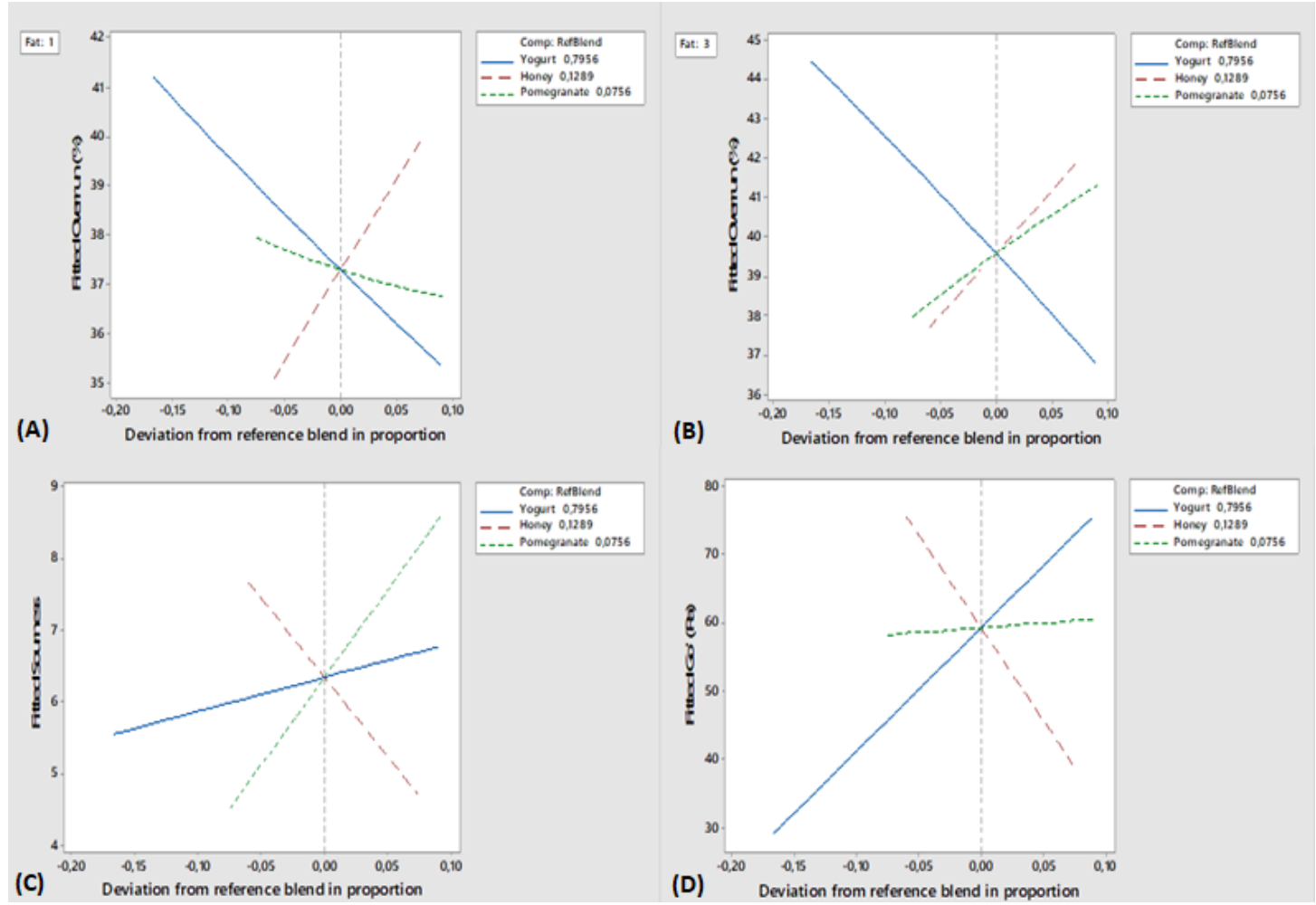

Figure 3. The Cox response trace plots at $1 \%$ and 3\% fat content levels corresponding to overrun (A and B, respectively), as well as the Cox response trace plot corresponding to sensory acidity (C) and $G^{\prime}(D)$. Graphs $C$ and $\mathrm{D}$ present the same effect of the factors on each response variable at both the fat levels (1\% and 3\%). The effect of yoghurt is marked in blue, the effect of honey is marked in red and the effect of the pomegranate juice is marked in green

$\mathrm{G}^{\prime}$ is the elasticity modulus $\left(\mathrm{G}^{\prime}\right)$ at $-2{ }^{\circ} \mathrm{C}$

The apparent viscosity of the samples at $-2{ }^{\circ} \mathrm{C}$ ranged from $0.354 \mathrm{~Pa} \cdot \mathrm{s}$ to $0.109 \mathrm{~Pa} \cdot \mathrm{s}$, while temperature increase resulted in decreasing viscosity values for all frozen yoghurt samples (Table 5). With the temperature increase, the mobility of the molecules also increases, as a result of which they show reduced resistance to flow and thus reduced viscosity.

Among rheological properties only $\mathrm{G}^{\prime}$ at $-2^{\circ} \mathrm{C}$ exhibited a reliable model and was further analyzed (in order for the specific cubic equation to fit the elements of a dependent variable, $\mathrm{R}^{2}$ must be at least $40 \%$ ).

The most important role in the change of $\mathrm{G}^{\prime}$ was played by honey, the increase of which led to a sharp decrease of the variable response (Figure 3D, Table 7). The effect of yoghurt was smaller, the increase of which resulted in increasing $\mathrm{G}^{\prime}$, when its concentration was increased at the expense of the amounts of other ingredients. The increase in pomegranate concentration had a negligible effect in $\mathrm{G}^{\prime}$, in relation to yoghurt and honey. Fat, as a process variable, did not affect the change of $\mathrm{G}^{\prime}$ at all, since no interaction of it with any of the components was found to be statistically significant. The increase in honey concentration causes the decrease in the freezing point of the ice cream mixture, and thus results in the formation of reduced number of ice crystals. The ice cream in this case appears soft with reduced hardness-consistency (Walstra et al., 2006). The formation of increased number of ice crystals contributes to an increase in the hardness-consistency of the samples. On the contrary, the increase in consistency caused by the increase in yoghurt concentration can be attributed to the decrease in honey concentration, which as mentioned above plays the most important role in the change of $\mathrm{G}^{\prime}$.

\subsection{Sensory Properties}

The complete analysis of the model, regarding the change of sensory acidity (Table 7, Figure 3C), is mainly based on the fact that yoghurt, had little effect on the acidity of the product, when compared to honey and 
pomegranate, while pomegranate exerted the greater action. Fat did not interact with any of the components and had no effect on samples acidity. Particularly, honey reduced samples acidity, pomegranate drastically increased their acidity and yoghurt increased acidity in a lesser degree. Panelists could distinguish to a significant extent the positive contribution of pomegranate juice to the acidity of the samples and to a lesser extent the decrease in acidity caused by the increase in the concentration of honey.

Regarding the individual action of the ingredients and that of the interaction in the color of the samples (Table 7 , Figure 4A and B), honey increased color intensity of the samples to yellow-brown, while pomegranate contributed in increasing pink color intensity. Yoghurt had a limited effect, in relation to pomegranate and honey, on color change, and at the lower level of fat content slightly increased the color, while at the upper level of its addition it decreased it more strongly. Honey, at 3\% fat concentration, increased the color more intense when compared to $1 \%$ fat content. On the other hand, the effect of increasing pomegranate concentration was practically similar between the two fat levels, reducing the color by a large step. Among other things, changing the amount of fat affects the color change and, when it interacts with honey and pomegranate, increases it. In addition, it affects the action of honey and pomegranate, since, at $1 \%$ fat content, honey mainly determines the color change, while when added at $3 \%$, pomegranate assumes this role. In addition, the positive effect of the interaction leads to increased color values, as shown in the Cox trace, especially in the maximum amount of honey and pomegranate added to frozen yoghurt samples. This effect is so important that gives the impression to the panelists that e.g. two samples with $15 \%$ pomegranate juice concentration and different fat content $(1 \%$ and $3 \%$ ) will be rated as "pink" and "white", respectively, as well as two samples with $18 \%$ honey concentration and different fat content (1\% and 3\%), may be rated as "white" and "yellow-brown", respectively. The results of the sensory evaluation are in agreement with those of the color measurement, in terms of the individual action of the different components. The interaction of fat with pomegranate and / or honey indicates the important role of fat in color. In particular, when fat content is high in the presence of honey, the carotenes that fat globules contain will increase the intensity of the yellow color. Conversely, when the fat content is high in the presence of pomegranate juice (which exhibits red color) it will increase the brightness of the samples due to increased light reflection caused by fat globules. Fat globules reflect light, increasing this way the intensity of white color of the samples (Walstra, et al., 2006).

Examining and describing the model that focuses on the variable of creaminess (Table 7, Figure 4C and D), one concludes that honey sharply increased the variable, when its concentration increased and those of pomegranate and yoghurt decreased. Pomegranate and yoghurt (pomegranate at a slower rate) reduced the creaminess and even faster at $1 \%$ fat content. In addition, at $3 \%$ fat concentration, honey increased creaminess at a slower rate than that at $1 \%$ fat content. Fat had a significant effect on the change of creaminess, as at $3 \%$ concentration the maximum value of creaminess (at $18 \%$ honey concentration) was significantly reduced ( 8.5 points) compared to the maximum value corresponding to $1 \%$ fat content (12.7 points). The decrease in fat content results in increasing the amount of the skimmed milk powder to be added in the ice cream mixture, as it can be seen in Table 3, and thus increasing the protein content of the samples. The proteins are well known for their ability to contribute to a smooth texture at the ice cream, through emulsification of the fat, foam formation and stability of the air bubbles (Goff \& Hartel, 2013). On the other hand, fat is responsible for a solid structure to be formed during freezing and therefore for consistency, appearance (dryness), and melting resistance. Thus, the increased fat content can results in the appearance of a granular texture in the ice cream, while low fat content contributes to a uniform creamy texture (Walstra et al., 2006). The simultaneously decrease in fat content and increase in protein concentration resulted in increasing the perception of samples creaminess by the panelists. As it concerns honey, the reduction of its addition rate leads to the formation of an increased number of ice crystals, and the possibility of creating a sandy texture that the panelists perceived as a lack of creaminess is increased. The decrease in creaminess with increasing yoghurt concentration is due to the possible decrease in honey concentration. 

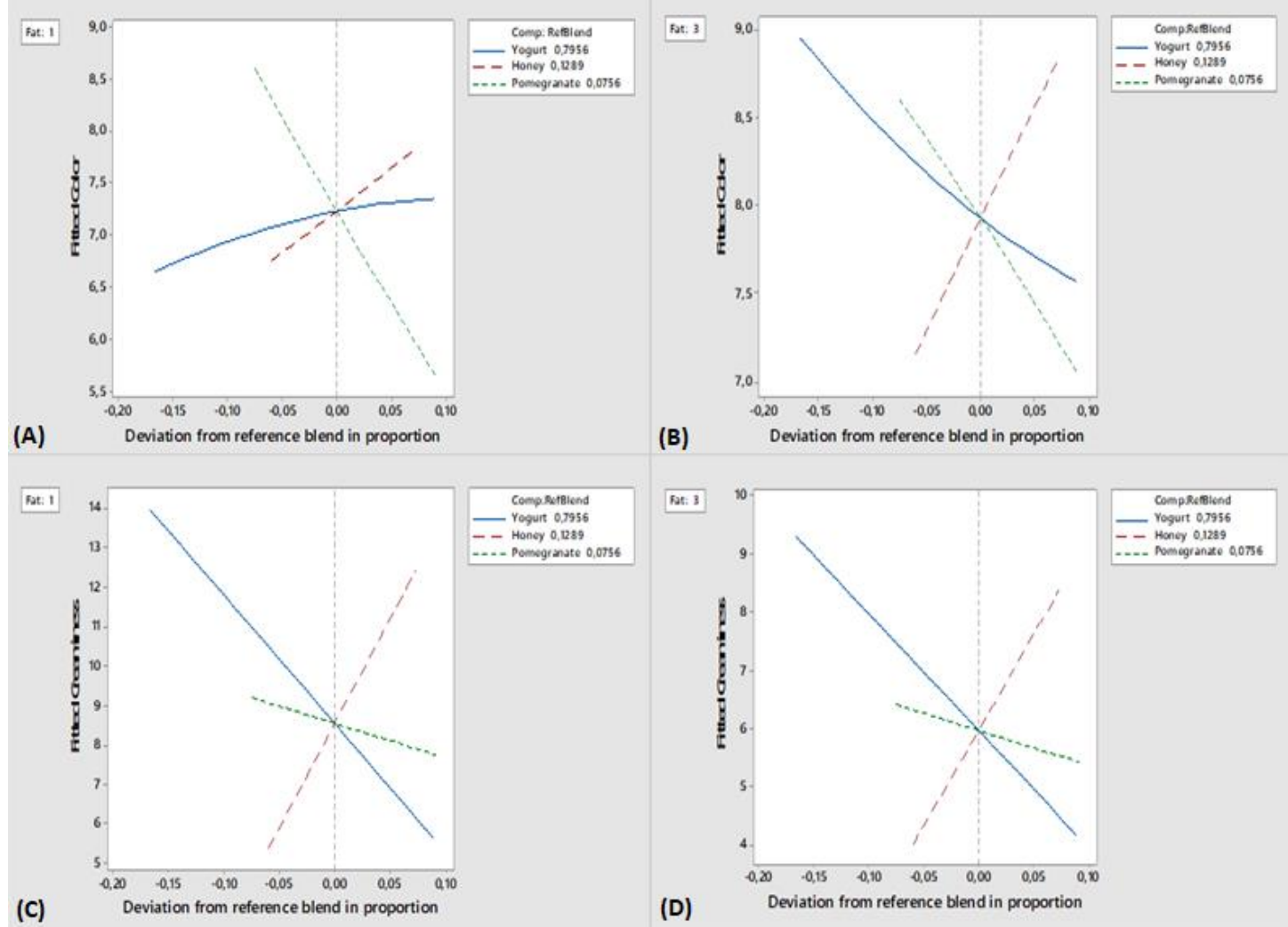

Figure 4. The Cox response trace plots at $1 \%$ and $3 \%$ fat content levels corresponding to color (A and B, respectively) and creaminess ( $\mathrm{C}$ and $\mathrm{D}$, respectively). The effect of yoghurt is marked in blue, the effect of honey is marked in red and the effect of the pomegranate juice is marked in green

The typical yoghurt taste of frozen yoghurt samples did not exhibit a reliable model and was not further analyzed.

By consulting Figure 5A, it becomes apparent that yoghurt increased the hardness of the samples, while honey reduced it (when the amount of yoghurt and pomegranate were reduced). Pomegranate, despite the size of the partial regression coefficient, had a negligible effect on hardness. Fat, as a process variable, did not affect the change in the variable response, as it did not interact with any of the components of the linear model (Table 7). The results of the sensory evaluation regarding the effect of the ice cream mixture ingredients on the hardness of the frozen yoghurt samples are in agreement with those of the rheological measurements.

As it can be seen in Figure 5B and by consulting the polynomial equation shown in Table 7, honey played a dominant role in increasing frozen yoghurt samples sweetness, while the action exerted by yoghurt (negative) and pomegranate (positive) in it was small to minimal, compared to that of honey. The fat did not affect the change in sweetness or the action of the terms of the linear model, as it did not interact with them and was not statistically significant. Based on the above, the panelists distinguished almost completely the change in sweetness depending on honey concentration. On the contrary, they did not discriminate the effect of pomegranate addition on samples sweetness, while they could notice the small reduction in samples sweetness caused by yoghurt. The sweet taste of frozen yoghurt samples is mainly due to the presence of honey. The slight decrease in sweetness intensity with yoghurt increase can be attributed to its acidic taste.

According to the Cox traces shown in Figure 5 (C and D) honey sharply increased the fattiness of the samples, with a relatively lower rate at $3 \%$ fat content. On the other hand, fattiness decreased when the amount of the added yoghurt was increased. Pomegranate caused a slight reduction in fattiness at both fat levels. The interaction of yoghurt with honey and fat had a negative effect on fattiness, which is indicated by the negative regression coefficients (Table 7), and this happens when fat content increases from $1 \%$ to $3 \%$, leading to reduced fattiness of the samples. This means that panelists evaluated a sample, with $1 \%$ fat content, as more fatty, while the sense of fattiness was reduced, when it had $3 \%$ fat. Since the effect of pomegranate on fattiness was very low 
compared to that of the other ingredients, increasing honey and decreasing yoghurt concentration increases the fattiness of the samples and the reverse change occurs when the percentage to yoghurt increases and that of honey decreases. The increase in fattiness with decreasing fat content may be attributed to the increase in creaminess caused by fat content reduction, as already explained. The same stands for yoghurt and honey effect on fattiness. In particular, the increase in the honey concentration and the decrease in the percentage of yoghurt led to an increase in creaminess and thus in fattiness.

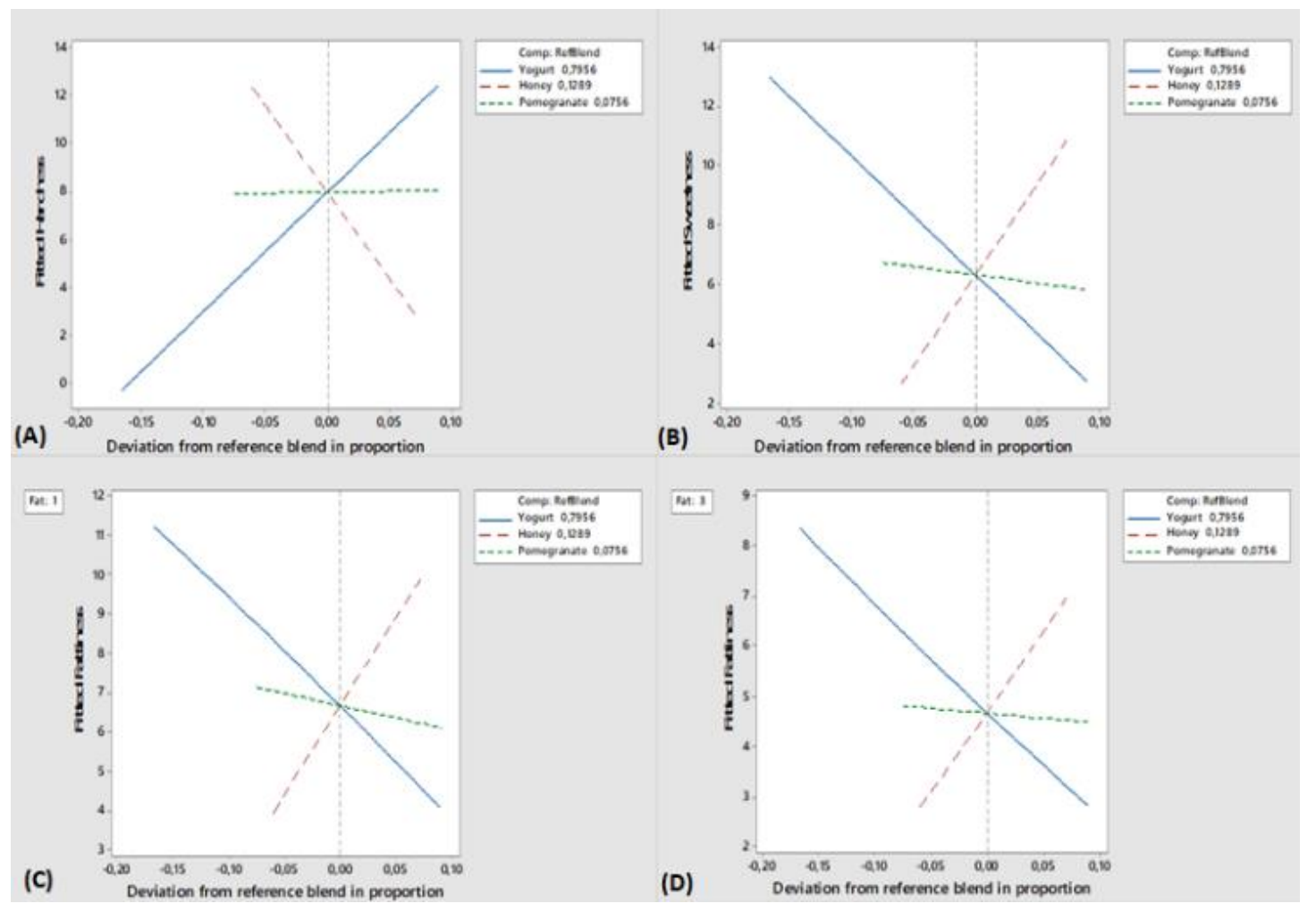

Figure 5. The Cox response trace plot corresponding to hardness (A) and sweetness (B), as well as the Cox response trace plots at $1 \%$ and $3 \%$ fat content levels corresponding to fattiness (C and D, respectively). Graphs $\mathrm{A}$ and $\mathrm{B}$ present the same effect of the factors on each response variable at both the fat addition levels (1\% and

$3 \%$ ). The effect of yoghurt is marked in blue, the effect of honey is marked in red and the effect of the pomegranate juice is marked in green

The proportion preference (Best-Worst scaling) for all treatments is shown in Figure 6. As it can be seen, sample 5 and control were the most preferable samples followed by samples $20,9,13,10,6,3$ and 8 . These results indicate that frozen yoghurt samples with honey and pomegranate juice addition were acceptable by the panelists. Furthermore, it seems that fat reduction did not affect panelists' preference, since the most acceptable frozen yoghurt sample (5) had $1 \%$ fat content and most of the preferred samples had low fat content $(9,10,6,3,8)$. However, further statistical analysis is required so as to find the optimum concentration of the ice cream mixture ingredients, according to panelists' preference. 


\begin{tabular}{|c|c|c|}
\hline $\begin{array}{l}\text { Ma rgin a } \\
\text { 1 Utility }\end{array}$ & $\begin{array}{r}\text { Marginal } \\
\text { Probabilit } \\
y\end{array}$ & $\begin{array}{l}\text { Treatment } \\
\mathrm{s}\end{array}$ \\
\hline 2.2539 & 0.2376 & 21 \\
\hline 2.2053 & $0.2263 \square$ & 5 \\
\hline 1.0807 & $0.0735 \longmapsto \div \quad 1 \quad: \quad 1$ & 20 \\
\hline 1.0436 & $0.0708 \square \square \quad 1 \quad 1 \quad 1 \quad 1$ & 9 \\
\hline 0.9570 & $0.0649 \square$ & 15 \\
\hline 0.7671 & 0.0537 以 $11+1 \quad 1$ & 10 \\
\hline 0.7309 & 0.0518 W $1: 1: 1:$ & $\sigma$ \\
\hline 0.6886 & $0.0497 \longmapsto 1: \quad 1 \quad: \quad 1$ & 3 \\
\hline 0.2212 & $0.0311 \square: 11: 1: 1$ & 8 \\
\hline-0.265 & $0.0191 \square: \quad 1 \quad 1 \quad 1 \quad 1$ & 7 \\
\hline-0.324 & $0.0180 \square: \quad 1 \quad 1 \quad 1 \quad 1$ & 4 \\
\hline-0.369 & $0.0172 \square: \quad 1 \quad 1 \quad \square$ & 2 \\
\hline-0.614 & $0.0135 \square: \quad \vdots \quad \vdots \quad: \quad \vdots$ & 16 \\
\hline-0.691 & $0.0125 \square: \quad \vdots \quad \vdots \quad: \quad: \quad \vdots$ & 18 \\
\hline-0.753 & $0.0117 \square: \quad \vdots \quad \vdots \quad \vdots \quad \vdots \quad \vdots$ & 19 \\
\hline-0.764 & $0.0116 \square: \quad \vdots \quad ; \quad|\quad| \quad \vdots$ & 13 \\
\hline-1.033 & $0.0089 n: \quad: \quad 1 \quad: \quad 1 \quad: \quad 1$ & 12 \\
\hline-1.097 & 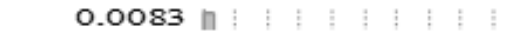 & 14 \\
\hline-1.244 & 0.0072 n: $1: 1: 1: 14$ & 17 \\
\hline-1.257 & 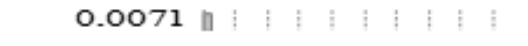 & 11 \\
\hline-1.537 & 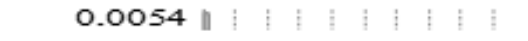 & 1 \\
\hline
\end{tabular}

Figure 6. The proportion preference per treatment (Best-Worst scaling). The positive values of the first column (Marginal Utility) correspond to the most preferable samples

\section{Conclusion}

Yoghurt, honey, pomegranate juice and fat content significantly affected frozen yoghurt properties. There was a good agreement between sensory evaluation results and instrumental measurements. Panelists' preference revealed that frozen yoghurt samples with honey and pomegranate juice addition exhibited favorable sensory properties. Fat reduction, followed by an increase in the amount of added skimmed milk powder and thus protein content, contributed in increasing samples creaminess and perception of fattiness, and at the same time did not affect panelists' preference. Further statistical analysis is required so as to find the optimum concentration of yoghurt, honey, pomegranate juice and fat in the novel dairy fermented frozen dessert.

\section{References}

AOAC. (1998). Acidity of milk, method no. 947.05 (16th ed.). In Official methods of analysis of AOAC International. Gaithersburg, MD, USA: AOAC International. p. 7.

Cruz, A. G., Antunes, A. E. C., Sousa, A-L. O. P., Faria, J. A. F., \& Saad, S. M. I. (2009). Ice-cream as a probiotic food carrier. Food Research International, 42, 1233-1239. https://doi.org/10.1016/j.foodres.2009.03.020

Deosarkar, S. S., Kalyankar, S. D., Khedkar, C. D., \& Sarode, A. R. (2016). Ice cream: Uses and method of manufacture. Encyclopedia of Food and Health, 3, 391-397. https://doi.org/10.1016/B978-0-12-384947-2.00384-6

Dimitreli, G., Petridis, D., Kapageridis, N., \& Mixiou, M. (2019). Effect of pomegranate juice and fir honey addition on the rheological and sensory properties of kefir-type products differing in their fat content. $L W T$ - Food Science and Technology, 111, 799-808. https://doi.org/10.1016/j.lwt.2019.05.071

Fernandez, M. A., Picard - Deland, E., Le Barz M., Daniel, N., \& Marette, A. (2017). Yogurt and Health. In J. Frias, C. Martinez-Villaluenga, \& E. Penas (Eds.), Fermented Foods in Health and Disease Prevention (pp. 305-338). London: Academic Press. https://doi.org/10.1016/B978-0-12-802309-9.00013-3

Gil, M. I., Tomàs-Barberàn, F. A., Hess-Pierce, B., Holcroft, D. M., \& Kader, A. A. (2000). Antioxidant activity 
of pomegranate juice and its relationship with phenolic composition and processing. Journal of Agricultural and Food Chemistry, 48, 4581-4589. https://doi.org/10.1021/jf000404a.

Goff, H. D., \& Hartel, R. W. (2013). Ice cream (7th ed.). New York, NY: Springer Science \& Business Media. https://doi.org/10.1007/978-1-4614-6096-1

Karabagias, I. K., Vavoura, M. V., Nikolaou C., Badeka, A. V., Kontakos, S., \& Kontominas, M. G. (2014). Floral authentication of Greek unifloral honeys based on the combination of phenolic compounds, physicochemical parameters and chemometrics. Food Research International, 62, 753-760. https://doi.org/10.1016/j.foodres.2014.04.015

Karimi, M., Kokini, J., \& Sadeghi, R. (2017). Pomegranate as a promising opportunity in medicine and nanotechnology. Trends in Food Science \& Technology, 69, 59-73. https://doi.org/10.1016/j.tifs.2017.08.019

Martinou-Voulasiki, I. S., \& Zerfiridis, G. K. (1990). Effect of some stabilizers on textural and sensory characteristics of yoghurt ice cream from sheep's milk. Institute of Food Technologists, 55, 703-707. https://doi.org/10.1111/j.1365-2621.1990.tb05211.x

Meo, S. A., Al - Asiri, S. A., Mahesar, A. L., \& Ansari, M. J. (2017). Role of honey in modern medicine. Saudi Journal of Biological Sciences, 24, 975-978. https://doi.org/10.1016/j.sjbs.2016.12.010

Omar, Z. B., Raphaelides, S., \& Kesteloot, R. (1995). Texture evaluation of french acid-type fresh cheeses. Journal of Texture Studies, 26, 325-338. https://doi.org/10.1111/j.1745-4603.1995.tb00969.x

Pinto, S. S., Fritzen-Freire, C. B., Munoz, I. B., Barreto, P. L. M., Prudencio, E. S., \& Amboni, R. D. M. C. (2012). Effects of the addition of microencapsulated Bifidobacterium BB-12 on the properties of frozen yogurt. Journal of Food Engineering, 111, 563-569. https://doi.org/10.1016/j.jfoodeng.2012.03.016

Salaün, F., Mietton, B., \& Gaucheron, F. (2005). Buffering capacity of dairy products. International Dairy Journal, 15, 95-109. http://dx.doi.org/10.1016/j.idairyj.2004.06.007

Sarkar, S., \& Chandra, S. (2019). Honey as a functional additive in yoghurt - a review. Nutrition \& Food Science, 50, 168-178. https://doi.org/10.1108/NFS-03-2019-0090

Tamime, A. Y., \& Robinson, R. K. (2000). Yoghurt. Science and technology (2nd ed.). Boca Raton, Boston, New York, Washington, DC: CRC Press.

Tamine, A. Y., \& Robinson, R. K. (2007). Tamine and Robinson's yogurt. Science and technology (3rd ed.). Boca Raton, Boston, New York, Washington, DC: CRC Press. https://doi.org/10.1533/9781845692612

Walstra, P., Wouters, J. T. M., \& Geurts, T. J. (2006). Dairy Science and Technology (2nd ed.). Boca Raton: Taylor \& Francis, CRC Press. https://doi.org/10.1201/9781420028010

\section{Copyrights}

Copyright for this article is retained by the author(s), with first publication rights granted to the journal.

This is an open-access article distributed under the terms and conditions of the Creative Commons Attribution license (http://creativecommons.org/licenses/by/4.0/). 